\title{
Communication barrier in family linked to increased risks for food insecurity among deaf people who use American Sign Language
}

\author{
Poorna Kushalnagar ${ }^{1} *$, Christopher J Moreland ${ }^{2}$, Abbi Simons ${ }^{3}$ and Tara Holcomb ${ }^{1}$ \\ 'Department of Psychology, Gallaudet University, 800 Florida Avenue NE, Washington, DC 20002, USA: \\ ${ }^{2}$ Department of Medicine, University of Texas Health Science Center at San Antonio, San Antonio, TX, USA: \\ ${ }^{3}$ Department of Science, Technology, Mathematics, Gallaudet University, Washington, DC, USA
}

Submitted 12 May 2017: Final revision received 16 August 2017: Accepted 23 August 2017: First published online 31 January 2018

\begin{abstract}
Objective: Food security is defined as being able to access enough food that will help maintain an active, healthy lifestyle for those living in a household. While there are no studies on food security issues among deaf people, research shows that communication barriers early in life are linked to poor physical and mental health outcomes. Childhood communication barriers may also risk later food insecurity.

Design/Setting/Subjects: A single food security screener question found to have $82 \%$ sensitivity in classifying families who are at risk for food insecurity was taken from the six-item US Household Food Security Survey Module. Questions related to food insecurity screener, depression diagnosis and retrospective communication experience were translated to American Sign Language and then included in an online survey. Over 600 deaf adult signers (18-95 years old) were recruited across the USA.

Results: After adjusting for covariates, deaf adults who reported being able to understand little to none of what their caregiver said during their formative years were about five times more likely to often experience difficulty with making food last or finding money to buy more food, and were about three times more likely to sometimes experience this difficulty, compared with deaf adults who reported to being able to understand some to all of what their caregiver said.

Conclusions: Our results have highlighted a marked risk for food insecurity and related outcomes among deaf people. This should raise serious concern among individuals who have the potential to effect change in deaf children's access to communication.
\end{abstract}

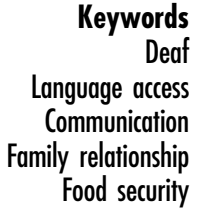

Food security is defined as all people being able to access enough food that will help maintain an active, healthy lifestyle ${ }^{(1)}$. One study estimates that $12.7 \%$ of American families lacked food security at some point in $2015^{(1)}$. Among those affected, food insecurity has been detrimental to their health and quality-of-life outcomes, resulting in higher depressive symptoms ${ }^{(2)}$. A small study with mothers suggests that the risk for food insecurity is much higher for those who reported multiple adverse childhood experiences ${ }^{(3)}$. Together, early-life stress such as adverse childhood experiences can impact later food insecurity and poorer mental health outcomes.

While there are no documented studies on food security issues among people who are deaf, research shows that poor mental health outcomes later in life are often linked to earlier difficulties with communication at home ${ }^{(4)}$. The link between communication access and later life skills is also supported in a sample of 618 German deaf adults ${ }^{(5)}$. A positive relationship was found between perceived parental support and career self-efficacy in deaf adolescents $^{(6)}$. Conversely, low parental involvement among deaf people has been found to be related to higher rates of unemployment and low independence ${ }^{(7)}$.

Some deaf people report missing out on important information about the family's health due to communication barriers ${ }^{(8)}$. Further, deaf people who experienced communication difficulties or reduced access to incidental information (e.g. overhearing conversations; hearing comments on the radio) earlier in life may not have the necessary background knowledge to accurately interpret 
health-care information that they gather ${ }^{(7)}$. When a deaf person experiences communication difficulties and presents with low health literacy, this deaf person may experience lower preventive screenings and vaccinations which could lead to lower health status and more chronic health problems than seen in the general population ${ }^{(9)}$. Research has reported a link between food insecurity and chronic diseases such as obesity and diabetes ${ }^{(10)}$. Given that poor health outcomes in some deaf people are linked to earlier communication difficulties ${ }^{(4,11,12)}$, the poor health outcomes associated with food insecurity can be prevented through promoting effective communication between caregivers and deaf children as well as schoolbased education about food management for older deaf children who are potentially at risk for food insecurity.

Given the strong links among adverse childhood experience, depression and food insecurity ${ }^{(13)}$, deaf people who retrospectively report reduced access to understanding caregiver's basic communication, regardless of modality, may be at greater risk for possible food insecurity later in life.

\section{Methods}

\section{Food security, depression and communication items}

One question, 'The food that I bought just didn't last, and I didn't have money to get more. Was that often, sometimes, or never true for (you/your household) in the last 12 months?', was taken from the six-item US Household Food Security Survey Module ${ }^{(14)}$. Response options included don't know. The single food question was chosen as a screener because this question was found to have $82 \%$ sensitivity in classifying families who are at risk for food insecurity and $95 \%$ specificity in identifying families who are food secure ${ }^{(15)}$.

A single item was taken from the Health Information National Trends Survey (hints.cancer.gov) to gather information about depression diagnosis: 'Has a doctor or other health professional ever told you that you had any of the following medical conditions: depression or anxiety disorder?' A set of retrospective communication items was taken from a previous study ${ }^{(4)}$. For these items, deaf adults were asked to choose a caregiver who took care of them the most and answer the subsequent questions about that caregiver's communication modality and the level of understanding caregiver's basic communication. 'Basic communication' is defined as being able to understand the person's utterances at the superficial level.

\section{Translation of food security, depression and} communication items into American Sign Language Items related to food security, depression diagnosis and retrospective communication experience were translated and back-translated by deaf bilingual professionals, and then tested for clarity and understanding in cognitive interviews with deaf people who had high school education or less (see Kushalnagar et al. ${ }^{(16)}$ for further details on the procedure). The final American Sign Language (ASL) videos were then included in an online survey and administered to deaf adults aged 18-95 years who used ASL as their primary language.

\section{Recruitment procedure}

After the university's Institutional Review Board approved the study procedures, the deaf research staff began recruitment through national channels that involve deaf community organizations and partners who use ASL. The study included those who self-reported using ASL, and excluded those who were 17 years old or younger as well as those who had unilateral hearing loss. The study enrolled those who provided their written consent. The online survey in ASL took approximately $1 \mathrm{~h}$ to complete. Each participant received a gratuity for participating in the study.

\section{Statistical analyses}

Descriptive statistics were used to summarize the sample characteristics. The $\chi^{2}$ test and bivariate correlation were used to describe the relationships among the variables. Multinomial logistic regression was used, with retrospective caregiver-child level of understanding basic communication as a main predictor and food security screener status as an outcome variable.

\section{Results}

At the time the study, a total of 642 deaf adults took the survey. About 5\% ( $n$ 33) chose 'don't know' for the food insecurity question and another $4 \%$ did not answer this question ( $n$ 27). An additional seventy-nine participants (14\%) did not answer the income question. Since the multinomial logistic regression model included demographic covariates such as age, income and education, responses to these questions were also required. Thus, our study sample was further reduced to 475 people who responded to all demographic, communication and food security questions (see Table 1). Of those who answered the food security screener, $8 \%$ 'often' experienced problems with buying food or not being able to make the food last, whereas $28 \%$ reported experiencing this 'sometimes'.

For the predictor in the multinomial logistic regression model, understanding caregiver's basic communication, approximately $8 \%$ of our sample reported retrospectively understanding 'little to none' of what their caregivers said. Another $22 \%$ understood 'some' of what the caregivers said. The remainder of the sample reported being able to understand 'most or all' of what their caregivers said. After partialling out for age, a significant relationship was found between retrospective level of understanding caregiver's communication and food security screener status (partial 
$r=0.15 ; P<0.001$ ). The caregiver's hearing status (deaf $v$. hearing) and the communication modality that the caregiver used with the youth were not associated with food security screener outcome. Nevertheless, these were entered in the model.

Table 2 lists results from a multinomial logistic regression model that was used to predict the probability of a deaf adult experiencing food insecurity. Consistent with the general literature, several covariates were identified as protective factors associated with food insecurity; people with higher education, higher income and no reported history of depression diagnosis were at lower risk for possible food insecurity. After controlling for these covariates, the main communication predictor was significantly associated with the food security outcome. Deaf adults who reported being able to understand 'little to none' of what their caregiver said during their formative

Table 1 Demographic characteristics, by frequency of difficulties in making food last or not having enough money to buy more, among deaf adult signers aged $18-95$ years $(n 475)$ participating in an online survey across the USA, April-July 2016 and October 2016-January 2017

\begin{tabular}{lccc}
\hline & 'Often' & 'Sometimes' & 'Never' \\
\hline Age (years), mean & 39 & 42 & 47 \\
SD & 14 & 17 & 17 \\
Female (\%) & 10 & 26 & 65 \\
Race = non-White (\%) & 10 & 35 & 55 \\
High school degree or lower (\%) & 13 & 39 & 48 \\
Unemployed† (\%) & 10 & 29 & 61 \\
Low income (\%) & 16 & 43 & 38 \\
Marital status = singleł (\%) & 69 & 65 & 47 \\
LGBTQ§ (\%) & 14 & 29 & 56 \\
Self-reported diagnosis of & 17 & 36 & 48 \\
$\quad$ depression (\%) & & & \\
Have deaf parents (\%) & 7 & 22 & 71 \\
\hline
\end{tabular}

fUnemployment includes those who are unemployed, students, retired and/ or disabled.

$\ddagger$ Single includes those who are divorced, widowed, separated and never married.

$\S$ Lesbian, gay, bisexual, transgender, queer. years were about five times more likely to 'often' experience difficulty with making food last or finding money to buy more food, and were about three times more likely to 'sometimes' experience this difficulty, compared with deaf adults who reported being able to understand 'some to all' of what their caregiver said.

\section{Discussion}

Our study is the first to describe the relationship between reported understanding of caregiver communication and food security among deaf adults. Since more than onethird of deaf participants reported at least occasional food insecurity (more than twice the general population estimate of $12 \%$ ), this group seems to be at even greater risk for malnutrition. Food insecurity correlated with participants' recall of limited access to parental communication, paralleling the impact of limited parental communication effectiveness on mental health, academic development and quality of life ${ }^{(17,18)}$. By linking poor parental communication access to food insecurity, our study thus provides another link to poor health outcomes.

There may be a number of potential reasons for this link. Whereas hearing children can acquire language incidentally, beginning at or before birth, deaf children whose caregivers do not use a signed language are at risk for language delay ${ }^{(19,20)}$. However, whether a caregiver used spoken or signed language did not correlate significantly with food security, nor did whether participants' parents were deaf or hearing; the more fundamental issue seems to be the caregiver-child communicative environment. Hearing caregivers, particularly those with lower socio-economic status or educational achievement, may lack access to resources needed to support effective communication and incidental learning for deaf children. Their clinical providers, such as primary-care physicians and audiologists, may not know how to obtain or recommend

Table 2 Summary of multinomial regression analysis results for retrospective communication and frequency of difficulties in making food last or not having enough money to buy more among deaf adult signers aged 18-95 years ( $n$ 475) participating in an online survey across the USA, April-July 2016 and October 2016-January 2017

\begin{tabular}{|c|c|c|c|c|c|c|}
\hline \multirow[b]{2}{*}{ Variable } & \multicolumn{3}{|c|}{$\begin{array}{l}\text { 'Often' experiences food } \\
\text { insecurity } †\end{array}$} & \multicolumn{3}{|c|}{$\begin{array}{l}\text { 'Sometimes' experiences food } \\
\text { insecurity } †\end{array}$} \\
\hline & $B$ & SE $(B)$ & OR & $B$ & $\mathrm{SE}(B)$ & OR \\
\hline Age & -0.362 & 0.178 & $0.696^{*}$ & -0.014 & 0.008 & $0.987^{*}$ \\
\hline Education & -0.220 & 0.135 & 0.803 & -0.205 & 0.086 & $0.814^{*}$ \\
\hline Income & $-2 \cdot 415$ & 0.473 & $0.090^{\star *}$ & -1.317 & 0.215 & $0.268^{\star *}$ \\
\hline Depression diagnosis & -1.386 & 0.388 & $0.250^{\star *}$ & -0.630 & 0.269 & $0.533^{*}$ \\
\hline Caregiver hearing status (deaf $v$. hearing) & -0.139 & 0.496 & 0.870 & 0.083 & 0.298 & 1.086 \\
\hline Caregiver communication modality $\ddagger$ & -0.088 & 0.286 & 0.916 & 0.052 & 0.192 & 1.053 \\
\hline \multicolumn{7}{|l|}{ Retrospective communication§ } \\
\hline Understood 'little to none' of what caregiver said & 1.540 & 0.607 & $4.779^{*}$ & 1.072 & 0.454 & $2.922^{*}$ \\
\hline Understood 'some' of what caregiver said & 0.792 & 0.458 & $2 \cdot 207$ & 0.271 & 0.311 & 1.311 \\
\hline
\end{tabular}

${ }^{\star} P<0.05,{ }^{*} P<0.01$.

†'Never' experienced food insecurity used as reference category.

$\ddagger$ Communication modalities include sign language and spoken language/other.

$\S$ Understood 'most or all' of what caregiver said used as reference category. 
such support. The lack of these family intervention services risks communication-related neglect for the deaf child ${ }^{(20)}$. While developmental and educational neglect in the USA have been well described, Humphries and colleagues ${ }^{(20)}$ introduced the concept of linguistic neglect. Deaf children who are language-deprived or not provided access to communication while growing up might feel ignored, which could qualify under emotional neglect that is often invisible. In our study, deaf individuals who retrospectively reported that they understood little to none of what their caregiver said were at significantly greater risk for not being able to make food last or not having money to buy more compared with deaf individuals who could understand some of what their caregivers said. This is consistent with the literature that reports a link between childhood maltreatment and later food insecurity as adults ${ }^{(21)}$.

Schools or programmes for deaf children will include some students who come from a household where communication barrier is a real issue. These students may potentially be at risk for later food insecurity. It is essential that home economics or physical education classes include lessons on managing food availability that affect people's health outcomes. These classes should also include health promotion concepts about identifying possible strategies to bring about changes related to food security. This information will not only benefit at-risk students but would raise all deaf students' awareness associated with accessing food and maintaining a healthy diet. As these deaf students become health literate about food and well-being, they can pass on their health knowledge to other deaf peers.

Our study has some limitations. We did not inquire about, nor could we directly describe, the depth of caregiver-child communication, nor were we able to access the demographics or perceptions of respondents' caregivers regarding communication experiences with their children. The retrospective nature of our survey cannot eliminate recall bias. A single food security screener was used. Strengths of the study include national representation of deaf participants, a robust multistage ASL translation process, a translation testing group of respondents with a range of educational achievement levels, and deaf research staff.

Our results have highlighted a marked risk for food insecurity and its known outcomes among deaf people. This should raise an alarm among public health stakeholders, educators, clinicians and policy makers who have the potential to effect change in deaf children's access to communication. By continuing to intervene at the individual, community and societal levels, we can continue to improve the health of and reduce health disparities impacting deaf people in the USA.

\section{Acknowledgements}

Financial support: This work was supported by National Institute on Deafness and Other Communication Disorders
(NIDCD) of the National Institutes of Health (P.K., grant numbers 7R01DC014463-02 and 7R15DC014816-02). The content is solely the responsibility of the authors and does not necessarily represent the official views of the National Institutes of Health. Conflict of interest: None. Authorship: P.K. designed the research; P.K. and A.S. analysed the data; P.K. and C.J.M. wrote the paper; T.H. provided technical assistance; and P.K. had primary responsibility for the final content. All authors read and approved the final manuscript. Ethics of human subject participation: The study was conducted according to the guidelines laid down in the Declaration of Helsinki and all procedures involving human subjects/patients were approved by Gallaudet University's Institutional Review Board. All participants provided their written consent.

\section{References}

1. Coleman-Jensen A, Rabbitt MP, Gregory CA et al. (2016) Household Food Security in the United States in 2015. Economic Reseach Report no. ERR-215, p. 36. Washington, DC: US Department of Agriculture, Economic Research Service.

2. Pruitt SL, Leonard T, Xuan L et al. (2016) Who is food insecure? Implications for targeted recruitment and outreach, National Health and Nutrition Examination Survey, 2005-2010. Prev Chronic Dis 13, E143.

3. Chilton M, Knowles M, Rabinowich J et al. (2015) The relationship between childhood adversity and food insecurity: 'It's like a bird nesting in your head'. Public Health Nutr 18, 2643-2653.

4. Kushalnagar P, Bruce S, Sutton T et al. (2017) Retrospective basic parent-child communication difficulties and risk of depression in deaf adults. J Dev Phys Disabil 29, 25-34.

5. Hintermair M (2008) Self-esteem and satisfaction with life of deaf and hard-of-hearing people - a resource-oriented approach to identity work. I Deaf Stud Deaf Educ 13, 278-300.

6. Michael R, Most T \& Cinamon R (2013) The contribution of perceived parental support to the career self-efficacy of deaf, hard-of-hearing, and hearing adolescents. J Deaf Stud Deaf Educ 18, 344-359.

7. Smith SR \& Samar VJ (2016) Dimensions of deaf/hard-ofhearing and hearing adolescents' health literacy and health knowledge. J Health Commun 21, Suppl. 2, 141-154.

8. Smith SR, Kushalnagar P \& Hauser PC (2015) Deaf adolescents' learning of cardiovascular health information: sources and access challenges. J Deaf Stud Deaf Educ 20, 408-418.

9. Berkman ND, Sheridan SL, Donahue KE et al. (2011) Low health literacy and health outcomes: an updated systematic review. Ann Intern Med 155, 97-107.

10. Seligman HK, Laraia BA \& Kushel MB (2010) Food insecurity is associated with chronic disease among low-income NHANES participants. $J$ Nutr 140, 304-310.

11. Kushalnagar P, Topolski TD, Schick B et al. (2011) Mode of communication, perceived level of understanding, and perceived quality of life in youth who are deaf or hard of hearing. J Deaf Stud Deaf Educ 16, 512-523.

12. Kuenburg A, Fellinger P \& Fellinger J (2016) Health care access among deaf people. J Deaf Stud Deaf Educ 21, $1-10$.

13. Sun J, Knowles M, Patel F et al. (2016) Childhood adversity and adult reports of food insecurity among households with children. Am J Prev Med 50, 561-572. 
14. Blumberg SJ, Bialostosky K, Hamilton WL et al. (1999) The effectiveness of a short form of the household food security scale. Am J Public Health 89, 1231-1234.

15. Hager ER, Quigg AM, Black MM et al. (2010) Development and validity of a 2 -item screen to identify families at risk for food insecurity. Pediatrics 126, e26-e32.

16. Kushalnagar P, Harris R, Paludneviciene R et al. (2017) Health Information National Trends Survey in American Sign Language (HINTS-ASL): protocol for the cultural adaptation and linguistic validation of a national survey. JMIR Res Protoc 6, e172.

17. Kaplan Toren N (2013) Multiple dimensions of parental involvement and its links to young adolescent self-evaluation and academic achievement. Psychol Sch 50, 634-649.
18. Choe S, Lim RS-H, Clark K et al. (2009) The impact of cervical cancer education for deaf women using a video educational tool employing American Sign Language, open captioning, and graphics. J Cancer Educ 24, $10-15$.

19. Moreland C, Atcherson SR, Zazove P et al. (2015) Hearing loss: issues in the deaf and hard of hearing communities. FP Essent 434, 29-40.

20. Humphries T, Kushalnagar P, Mathur G et al. (2016) Avoiding linguistic neglect of deaf children. Soc Serv Rev $\mathbf{9 0}$, 589-619.

21. Chapman DP, Whitfield CL, Felitti VJ et al. (2004) Adverse childhood experiences and the risk of depressive disorders in adulthood. $J$ Affect Disord 82, 217-225. 